\section{Relationship Between Renal Dysfunction and Severity of Coronary Artery Disease in Japanese Patients - Reply -}

Dr Oda gave us important suggestions with respect to the role of dyslipidemia in the so-called cardiorenal syndrome. Dyslipidemia is one of the conventional and well-established risk factors for coronary artery disease (CAD). Among the cholesterol fractions, low-density lipoprotein cholesterol (LDL-C) has been especially targeted by lipid-lowering therapy to prevent $\mathrm{CAD}$, because lowering LDL-C with statins has been found to significantly reduce the relative risk for major vascular events as compared with placebo. ${ }^{1}$ High-density lipoprotein cholesterol (HDL-C) is also important because several studies have found low HDL-C significantly related to the possibility of developing CAD..$^{2,3}$ However, at present there is no direct way medically intervening to change the level of HDL-C.

In the past years, some researchers reported that dyslipidemia was somehow related to the development of renal dysfunction. Schaeffner et al reported that in apparently healthy men, elevated total cholesterol (TC), high non-HDL-C, a high ratio of TC/HDL, and low HDL-C were significantly associated with an increased risk for developing renal dysfunction (creatinine $\geq 1.5 \mathrm{mg} / \mathrm{dl}$ ) after 14 years. ${ }^{4}$ Using multiple regression analysis, Tozawa et al demonstrated that in the Japanese general population, HDL-C in men and triglycerides in women, but not LDL-C, significantly correlated with deterioration in glomerular filtration rate (GFR) after 3 years. ${ }^{5}$

\begin{tabular}{|c|c|c|c|c|c|}
\hline & \multicolumn{2}{|c|}{ Univariate analysis } & \multicolumn{3}{|c|}{ Multivariate analysis $\left(r^{2}=0.1387\right)$} \\
\hline & $\mathbf{r}^{2}$ & $P$ value & $\beta$ & f value & $P$ value \\
\hline Age & 0.0007 & 0.5173 & 0.0768 & 1.6826 & 0.0928 \\
\hline Sex & 0.0130 & 0.0064 & 0.1263 & 2.8077 & 0.0052 \\
\hline BMI & 0.0117 & 0.0099 & 0.0035 & 0.0792 & 0.9369 \\
\hline Hypertension & 0.0024 & 0.2382 & -0.0038 & -0.0904 & 0.9280 \\
\hline Systolic BP & 0.0068 & 0.0515 & 0.0616 & 1.1992 & 0.2310 \\
\hline Diastolic BP & 0.0007 & 0.5234 & -0.0108 & -0.2147 & 0.8301 \\
\hline FPG & 0.0348 & $<0.0001$ & 0.1845 & 4.4345 & $<0.0001$ \\
\hline HDL-C & 0.0439 & $<0.0001$ & -0.1511 & -3.2664 & 0.0012 \\
\hline LDL-C & 0.0247 & 0.0002 & 0.1548 & 3.7164 & 0.0002 \\
\hline Triglycerides & 0.0129 & 0.0066 & 0.0229 & 0.5186 & 0.6042 \\
\hline Smoking habit & 0.0053 & 0.0831 & 0.0352 & 0.8399 & 0.4013 \\
\hline CKD & 0.0266 & 0.0001 & 0.1412 & 3.3780 & 0.0008 \\
\hline
\end{tabular}

$\mathrm{BMI}$, body mass index; BP, blood pressure; FPG, fasting plasma glucose; HDL-C, high-density lipoprotein cholesterol; LDL-C, low-density lipoprotein cholesterol; CKD, chronic kidney disease.

\begin{tabular}{|c|c|c|c|c|c|}
\hline & \multicolumn{2}{|c|}{ Univariate analysis } & \multicolumn{3}{|c|}{ Multivariate analysis $\left(r^{2}=0.1576\right)$} \\
\hline & $\mathbf{r}^{2}$ & $P$ value & $\beta$ & f value & $P$ value \\
\hline Age & 0.0031 & 0.1828 & 0.0860 & 1.7574 & 0.0795 \\
\hline Sex & 0.0041 & 0.1244 & -0.0389 & -0.8177 & 0.4139 \\
\hline BMI & 0.0001 & 0.8558 & -0.0094 & -0.2043 & 0.8382 \\
\hline Hypertension & 0.0001 & 0.7903 & -0.0572 & -1.3224 & 0.1866 \\
\hline Systolic BP & 0.0351 & $<0.0001$ & 0.1459 & 2.7773 & 0.0057 \\
\hline Diastolic BP & 0.0069 & 0.0488 & 0.0205 & 0.3965 & 0.6919 \\
\hline FPG & 0.0238 & 0.0002 & 0.0830 & 1.8811 & 0.0605 \\
\hline HDL-C & 0.0003 & 0.6903 & 0.0028 & 0.0571 & 0.9545 \\
\hline LDL-C & 0.0098 & 0.0181 & 0.0858 & 1.9515 & 0.0516 \\
\hline Triglycerides & 0.0031 & 0.1849 & 0.0532 & 1.1579 & 0.2474 \\
\hline Smoking habit & 0.0021 & 0.2736 & 0.0097 & 0.2218 & 0.8246 \\
\hline Baseline GFR & 0.0135 & 0.0053 & 0.1815 & 4.0122 & 0.0001 \\
\hline LVEF & 0.0045 & 0.1092 & -0.0359 & -0.7897 & 0.4301 \\
\hline Plasma BNP & 0.0468 & $<0.0001$ & 0.2013 & 4.1966 & $<0.0001$ \\
\hline No. of stenotic coronary arteries & 0.0399 & $<0.0001$ & 0.1068 & 2.2292 & 0.0262 \\
\hline $\begin{array}{l}\text { No. of } \mathrm{CAG} \text { and } \\
\mathrm{PCl} \text { per patient during follow-up }\end{array}$ & 0.0118 & 0.0094 & 0.0483 & 1.0614 & 0.2890 \\
\hline
\end{tabular}

GFR, glomerular filtration rate; LVEF, left ventricular ejection fraction; BNP, B-type natriuretic peptide; CAG, coronary angiography; $\mathrm{PCl}$, percutaneous coronary intervention. Other abbreviations see in Table 1. 
If we consider the results of those studies, LDL-C, although well established as one of the most important risk factors for $\mathrm{CAD}$, seems to play a lesser role in the development of renal insufficiency. However, recently, at least crosssectionally, Oda and Kawai reported that in Japanese men, the levels of LDL-C increased significantly in relation to the stage of chronic kidney disease (CKD), ${ }^{6}$ which contradicts the previously reported data.

Based on their findings, Dr Oda pointed out the potential effects of lipid-related factors on our results concerning the relationship between renal dysfunction and severity of CAD in Japanese patients. ${ }^{7}$ In fact, there are many possible mechanisms for the progression of both renal dysfunction and CAD, with dyslipidemia probably being one of them. Dyslipidemia may lead to renal damage through atherosclerosis of the renal arterioles and other mechanisms. On the other hand, dyslipidemia is associated with renal damage through substantial urinary excretion of protein.

We adopted a morbidity rate instead of the numeric data of fasting plasma glucose (FPG), HDL-C, LDL-C or triglycerides to analyze the effect of diabetes mellitus or dyslipidemia on the progression of renal dysfunction, because our patient setting was limited to inpatients suspected of having CAD. Some of them had already started to be treated medically and the numeric data per se may lead us to underestimate their real risks. However, we may be able to add some information by showing those data, as Dr Oda indicated: FPG $123.5 \pm 45.1 \mathrm{mg} / \mathrm{dl}$; HDL-C $49.8 \pm 13.6 \mathrm{mg} / \mathrm{dl}$; LDL-C $119.3 \pm$ $31.6 \mathrm{mg} / \mathrm{dl}$; triglycerides $143.5 \pm 85.7 \mathrm{mg} / \mathrm{dl}$ (mean $\pm \mathrm{SD}$ ). We performed multiple regression analysis using the number of stenotic coronary arteries as a dependent variable and risk factors such as age, sex, body mass index, conventional risk factors, including lipids and CKD, as independent variables. In our results, CKD was still an independent risk factor of coronary artery stenosis (Table 1). Moreover, stepwise multiple regression analysis showed that the number of stenotic coronary arteries was independently and significantly associated with GFR deterioration, even after including the numeric data instead of the morbidity rate of diabetes mellitus or dyslipidemia (Table 2). FPG and LDL were significantly associated with GFR deterioration if analyzed univariately, although neither was when subjected to multivariate analysis, which may be related to medical intervention for diabetes mellitus or dyslipidemia, or to instability of the effect of each cholesterol fraction on the progression of renal dysfunction.

\section{References}

1. Downs JR, Clearfield M, Weis S, Whitney E, Shapiro DR, Beere PA, et al. Primary prevention of acute coronary events with lovastatin in men and women with average cholesterol levels: Results of AFCAPS/TexCAPS. JAMA 1998; 279: 1615-1622.

2. Assmann G, Schulte H, von Eckardstein A, Huang Y. High-density lipoprotein cholesterol as a predictor of coronary heart disease risk: The PROCAM experience and pathophysiological implications for reverse cholesterol transport. Atherosclerosis 1996; 124(Suppl): $11-20$.

3. Washio M, Sasazuki S, Kodama H, Yoshimasu K, Liu Y, Tanaka $\mathrm{K}$, et al. Role of hypertension, dyslipidemia and diabetes mellitus in the development of coronary atherosclerosis in Japan. Circ J 2001; 65: 731-737.

4. Schaeffner ES, Kurth T, Curhan GC, Glynn RJ, Rexrode KM, Baigent $C$, et al. Cholesterol and the risk of renal dysfunction in apparently healthy men. J Am Soc Nephrol 2003; 14: 2084-2091.

5. Tozawa M, Iseki K, Iseki C, Oshiro S, Ikemiya Y, Takishita S. Triglyceride, but not total cholesterol or low-density lipoprotein cholesterol levels, predict development of proteinuria. Kidney Int 2002; 62: 1743-1749.

6. Oda E, Kawai R. Low-density lipoprotein cholesterol (LDL) is cross-sectionally associated with preclinical chronic kidney disease (CKD) in Japanese men. Intern Med 2010; 49: 713-719.

7. Kiyosue A, Hirata Y, Ando J, Fujita H, Morita T, Takahashi M, et al. Relationship between renal dysfunction and severity of coronary artery disease in Japanese patients. Circ J 2010; 74: 786-791.

Arihiro Kiyosue, $\mathrm{MD}, \mathrm{PhD}$

Yasunobu Hirata, MD, PhD

Department of Cardiovascular Medicine, Graduate School of Medicine, University of Tokyo, Tokyo, Japan

(Released online June 1, 2010) 